\title{
ANÁLISE DA PAISAGEM RIBEIRINHA DOS BAIRROS DA ZONA CENTRO/NORTE EM TERESINA, PIAUÍ
}

ANÁLISIS DEL PAISAJE RIBEREÑO DE LOS BARRIOS DEL CENTRO / ZONA NORTE DE TERESINA,
PIAUII

ANALYSIS OF THE RIVERSIDE LANDSCAPE OF THE NEIGHBORHOODS OF THE CENTER/NORTH ZONE IN TERESINA, PIAUÍ

\section{MATOS, KARENINA CARDOSO}

Doutora, professora do Departamento de Construção Civil e Arquitetura da Universidade Federal do Piauí- UFPI. Coordenadora do Laboratório Urbano da Paisagem - LUPA/UFPI. E-mail: karenina@ufpi.edu.br

\section{SANTIAGO, DENISE RODRIGUES}

Pós-Graduanda em Paisagismo e Design de Interiores - IPOG e Graduada em Arquitetura e Urbanismo pela Universidade Federal do Piauí. E-mail: arq.denise15@gmail.com

\section{LOPES, WILZA GOMES REIS}

Doutora, professora titular do Departamento de Construção Civil e Arquitetura e do Mestrado e Doutorado em Desenvolvimento e Meio Ambiente da Universidade Federal do Piauí - UFPI. Coordenadora do Laboratório Urbano da Paisagem - LUPA/UFPI. E-mail wilza@ufpi.edu.br

\section{SILVA, ISABELLE MARIA GONÇALVES PEREIRA}

Graduanda em Arquitetura e urbanismo pela Universidade Federal do Piaui - UFPI. E-mail isabellemgps27@gmail.com

\section{LEITE, NÍCIA BEZERRA FORMIGA}

Doutora, professora do Departamento de Construção Civil e Arquitetura da Universidade Federal do Piauí- UFPI. E-mail nicialeite@ufpi.edu.br

\section{RESUMO}

Essa pesquisa tem como objetivo analisar a paisagem ribeirinha da zona Centro/Norte da cidade de Teresina, capital do estado do Piaú, identificando as diferentes paisagens e como elas foram se modificando a partir do Plano de 2006 até os dias atuais, destacando elementos importantes que favorecem ou não a conexão do meio urbano com a paisagem ribeirinha. Para embasamento teórico foram abordados conceitos de rios urbanos, paisagem ribeirinha e espaços livres, contribuindo para a realização das análises a respeito da paisagem dos rios Parnaíba e Poti no recorte de estudo. Foi realizada uma análise qualitativa com o intuito de diagnosticar aspectos relacionados às questões sociais, urbanos e ambientais. Foram realizadas também visitas in loco, registro através de fotografias, levantamento de imagens de satélite, e, elaboração de capas urbanas e sobreposições com a região dividida em nove cenários. Quanto aos dados levantados, foi possível perceber as diferentes paisagens e as potencialidades dos rios, entre as quais vale destacar: (a) as paisagens que se completam pelas atividades de subsistência, como as hortas comunitárias e a pesca; (b) as paisagens que se identificam por áreas inundáveis, por parques ambientais ou por ocupações irregulares; e (c) uma paisagem mais centrada nas trocas comerciais, quando correspondente ao Centro da cidade.

PALAVRAS-CHAVE: espaços livres; paisagem ribeirinha; rio poti; rio parnaíba.

\section{RESUMEN}

Esta investigación tiene como objetivo analizar el paisaje ribereño en la zona Centro / Norte de la ciudad de Teresina, capital del estado de Piauí, identificando los diferentes paisajes y cómo cambiaron desde el plan de 2006 hasta la actualidad, destacando elementos importantes que favorecen o favorecen no la conexión del entorno urbano con el paisaje ribereño. Para la fundamentación teórica se abordaron conceptos de ríos urbanos, paisaje ribereño y espacios abiertos, contribuyendo a la realización de análisis del paisaje de los ríos Parnaíba y Poti en el recorte de estudio. Se realizó un análisis cualitativo con el fin de diagnosticar aspectos relacionados con la problemática social, urbana y ambiental. También se realizaron visitas in situ, registro a través de fotografías, relevamiento de imágenes satelitales y elaboración de cubiertas urbanas y superposiciones con la región dividida en nueve escenarios. En cuanto a los datos recolectados, fue posible percibir los diferentes paisajes y potencialidades de los ríos; entre ellas cabe destacar: (a) los paisajes que se complementan con actividades de subsistencia, como los huertos comunitarios y la pesca; (b) paisajes que se identifican por áreas inundables, parques ambientales u ocupaciones irregulares; y (c) un paisaje más centrado en los intercambios comerciales, cuando corresponde al Centro de la ciudad.

PALABRAS CLAVE: espacios libres; paisaje ribereño; río poti; río parnaíba. 


\begin{abstract}
This research aims to analyze the riverside landscape in the Center/North zone of the city of Teresina, capital of the state of Piaui, identifying the different landscapes and how they changed from the 2006 plan to the present day, highlighting important elements that favor or not the connection of the urban environment with the riverside landscape. For theoretical foundation, concepts of urban rivers, riverside landscape and open spaces were addressed, contributing to the realization of analyzes of the landscape of the Parnaíba and Poti rivers in the study cutout. A qualitative analysis was carried out in order to diagnose aspects related to social, urban and environmental issues. On-site visits were also carried out, registration through photographs, survey of satellite images, and elaboration of urban covers and overlays with the region divided into nine scenarios. As for the data collected, it was possible to perceive the different landscapes and potential of the rivers. It is worth mentioning: (a) the landscapes that are complemented by subsistence activities, such as community gardens and fishing; (b) landscapes that are identified by floodable areas, environmental parks, or irregular occupations; and (c) a landscape more centered on commercial exchanges, when corresponding to the Center of the city. KEYWORDS: open spaces; riverside landscape; poti river; parnaíba river.
\end{abstract}

Recebido em: 17/12/2020 Aceito em: .10/08/2021

\title{
1 INTRODUÇÃO
}

O processo de urbanização desordenado e o crescimento populacional, afetam diretamente os rios e suas margens, causando efeitos negativos como o aumento dos riscos de inundação, a destruição da mata ciliar, problemas relacionados com a saúde pública, além de afetar a permeabilidade física e visual. Essas questões vêm sendo discutidas em todo o mundo, e a partir do século XX, essas discussões chegaram no Brasil e consequentemente na cidade de Teresina, capital do estado do Piauí. Com isso, vários instrumentos regulatórios foram criados, a fim de preservar os corpos hídricos e tentar integrá-los à cidade. Porém, enfatiza-se, que as legislações ao mesmo tempo que tentaram preservar as margens dos rios, também impediram a integração dos corpos hídricos com o meio urbano, como é o caso da cidade de Teresina, que se desenvolveu em função dos rios Parnaíba e Poti, tendo a influência destes na sua expansão urbana (MATOS, 2017).

Os rios representam um elemento natural marcante nas paisagens, visto que a água é um recurso abundante no mundo. Eles trazem o natural para dentro das cidades em função da sua riqueza biológica e valor geomorfológico, representando um ganho para os ambientes urbanos quando conseguem se conectar, efetivamente, com os mesmos. É importante preservá-los e valorizá-los, pois, possuem grande relevância para a construção das paisagens urbanas, apresentando uma relação singular entre sua composição espacial e seu uso, que varia em função das particularidades de cada lugar (MACEDO, 1999).

As paisagens ribeirinhas, enquanto cenários das relações ambientais e sociais, são capazes de serem atores principais nas cidades, pois sua linearidade traz o equilíbrio de espaços verdes essenciais para qualidade de vida urbana e ambiental. E para que esse espaço seja duradouro, é necessário conhecer, planejar e saber conduzir, não basta limitar uma porcentagem de área verde por habitantes, por exemplo, mas sim que esses espaços estejam distribuídos de forma equilibrada, que sejam apropriados e que realizem diferentes funções ambientais e urbanas e que potencialize seu entorno (MATOS, 2017, p. 23).

Dessa maneira, a pesquisa se desenvolveu acerca das duas frentes ribeirinhas do rio Parnaíba e do rio Poti, no intervalo correspondente à zona Centro/Norte, dentro da qual encontram-se 7 pontes, 25 bairros e 14 parques. Tais bairros tem uma relação muito forte com o rio, principalmente pelas atividades de subsistência, porém ainda são áreas pouco valorizadas pelo poder público, apesar do seu potencial paisagístico. Portanto, o objetivo do estudo é analisar a paisagem ribeirinha da zona Centro/Norte de Teresina, identificando as diferentes paisagens e como elas foram se modificando a partir do plano 2006 até os dias atuais. Para tanto, baseou-se em pesquisas bibliográficas, levantamentos técnicos a respeito do tema, visitas in loco, fotografias e análises de mapas por meio da identificação de cenários.

O estudo possui uma análise qualitativa com o intuito de diagnosticar aspectos relacionados às questões sociais, urbanos e ambientais. Quanto aos dados levantados, foi possível perceber a evolução da ocupação no decorrer das décadas que vai sendo marcada pelo surgimento de empreendimentos comerciais e pelo intenso adensamento com a consequente diminuição das áreas verdes, apesar de ainda existirem terrenos vazios nas frentes ribeirinhas como ocorre em bairros além do rio Poti.

\section{PROCEDIMENTOS METODOLÓGICOS}

Este trabalho foi desenvolvido a partir de contextos relacionados à incorporação da natureza no ambiente urbano. O referencial teórico foi baseado em informações sobre a cidade de Teresina, com enfoque na zona 
Centro/Norte, nos instrumentos regulatórios e nos conceitos relacionados ao tema que foram aplicados como elementos para a leitura da paisagem.

Foram realizadas pesquisas bibliográficas baseadas em fontes especializadas, abrangendo livros, teses, dissertação, dados documentais, estudo dos planos urbanísticos, planos diretores, leis e decretos municipais direcionados às políticas urbanas de legislação ambiental, a fim de compreender a área de estudo. Sobre a expansão urbana de Teresina, fundamentou-se em autores locais como Chaves (1987), Façanha (1998) e AUTOR (2017). Já sobre o estudo de conceitos centrais como espaços livres públicos foram baseados em autores como Macedo (1995), Pellegrino (2006) e Magnoli (2006). Assim como também paisagem ribeirinha por Saraiva (1999) e Mello (2008). Toda essa contextualização propiciou a análise da paisagem ribeirinha da zona Centro/Norte permitindo a leitura das transformações que ocorreram ao longo do tempo, quanto aos usos e apropriação dos espaços.

A análise das transformações ocorridas nas frentes ribeirinhas dos rios Poti e Parnaíba no recorte analisado foram realizadas com o apoio de mapas cartográficos, fotografias aéreas e imagens de satélite, coletadas na Prefeitura e na internet, bem como, análise das relações locais da estrutura urbana para tentar identificar o seu papel e sua importância no processo de urbanização, preservação, urbanidade e qualidade da cidade através de visitas in loco, levantamento fotográfico, croquis e mapas esquemáticos. Em síntese, foi realizada uma análise geral por meio da identificação de cenários, para o que foram considerados o percurso, a morfologia e a urbanidade.

\section{OS ESPAÇOS LIVRES E A PAISAGEM}

As conceituações de espaços livres são bastante abrangentes. Segundo Macedo (1995), espaços verdes, áreas verdes, áreas de lazer e áreas de circulação estão enquadradas dentro desse termo. Analisados dentro do contexto urbano, são espaços livres: "ruas, praças, largos, pátios, quintais, parques, jardins, terrenos baldios, corredores externos, vilas, vielas e outros mais por onde as pessoas fluem no seu dia a dia em direção ao trabalho, ao lazer ou a moradia" (MACEDO, 1995, p.16). Assim, é válido compreender a conceituação específica dada para espaços verdes, sendo eles:

Toda área urbana ou porção do território ocupada por qualquer tipo de vegetação e que tenham um valor social. Neles estão contidos bosques, campos, matas, jardins, alguns tipos de praças e parques, etc. [...]. O valor social atribuído pode ser vinculado ao seu utilitarismo [...], ao interesse para a conservação ou preservação de conjuntos de ecossistemas [...], ao seu valor estético/cultural e mesmo a sua destinação para o lazer ativo ou passivo (MACEDO, 1995, p.16).

Macedo (1995, p. 49) reitera ainda que "a não formalização de um sistema completo de espaços livres para lazer [...] se observa como resposta a internalização do lazer em praças, parques e clubes privados [...] que cumprem as funções antes destinadas prioritariamente aos espaços públicos". De fato, a procura por espaços livres cresceu consideravelmente nos últimos anos, tanto quando se fala em setor público como também no privado. Em muitos casos, nesses espaços é permitido somente a mínima intervenção do homem, refletindo muitas vezes ao não atendimento das demandas sociais e ecológicas (SOUZA, MACEDO, 2014)

Outro ponto importante sobre os espaços livres é o fato de oferecerem urbanidade, conceito definido por Mello (2008) no sentido de promover (ou não) a interação entre as pessoas e destas com o meio. Nos casos em que a intervenção humana é necessária para melhorar (ou mesmo incentivar) essa relação, é essencial que não se tenha uma visão estritamente urbanística, que pode desconsiderar as funções ambientais das margens, uma vez que "a qualidade essencial dessas intervenções consiste na promoção do convívio social e no resgate das relações de contato da população com os corpos d'água, o que por sua vez, corresponde ao conceito de urbanidade" (MELLO, 2008, p. 303). Sob esta perspectiva é importante mencionar que:

[...] os conceitos sobre planejamento ambiental ou da paisagem confundem-se erroneamente com os próprios de projetos paisagísticos. Nestes trabalhos, em geral, a destinação ou definição dos usos é feita sem a consideração de aspectos teóricos e metodológicos de planejamento ambiental e sem a incorporação de aspectos ecológicos. Nesse contexto, são reservados a "áreas verdes" os espaços não incorporados pelos projetos em lotes ou sistema viário, e que não serviriam para outros usos, seja pela legislação ou por dificuldades técnicas e econômicas para sua comercialização (PELLEGRINO, 2006, p. 61). 
Portanto, faz-se necessário planejar os espaços livres de beira-d'água de modo a que não se tornem áreas desvalorizadas e para que sigam o movimento de resgate dos frontais aquáticos, ideia típica da virada do milênio (MELLO, 2008). Portanto, há necessidade de compreender os rios e suas margens como elementos essenciais no que se refere aos espaços livres urbanos, com intuito de obter uma relação adequada entre eles e a cidade, considerando os meios sociais e culturais (SOUZA, MACEDO (2014).

Nesse campo, Sant'Anna (2020) defende uma visão ampla acerca do conceito de paisagem, ressaltando a importância de se compreender e de se valorizar o lugar, assim como evidenciar e destacar as qualidades bióticas e abióticas do meio ambiente.

Para Magnoli (2006) a ampliação das necessidades do ser humano e a expansão do seu campo de conhecimentos ampliaram o processo de criação de paisagens sobre o planeta, de modo que a paisagem pode ter diversos significados, a depender da referência e da disciplina. Em síntese "a morfologia da paisagem é a resultante da interação ente a lógica própria dos processos do suporte (sistemas geológico e climático) e a lógica própria dos processos sociais e culturais (antrópica)" (Idem, p. 178). Especificamente sobre as paisagens urbanas, ela afirma que:

A lógica própria dos processos do homem se apresenta por expressões físicas (parcelamentos, escavações, plantações, construções, edificações, etc.) em expressões físicas que apresentam a lógica dos processos do suporte (geologia e clima, solo, relevo, vegetação e sol, água e ventos). Na paisagem urbana essas expressões físicas se manifestam sobre o solo em espaços edificados e espaços não-edificados (Ibidem, p.179)

Por sua vez, Sales (2015) ressalta que a paisagem é um sistema dinâmico que envolve todos os seres vivos, sejam eles animais, plantas e o próprio homem, atuando sobre um espaço físico com interação mútua. Destaca-se ainda que essa relação resulta em uma imagem com determinadas características e identidade.

\section{RIOS URBANOS E PAISAGEM RIBEIRINHA}

Saraiva (1999) afirma que os rios são elementos estruturadores do meio ambiente urbano. E, a história das cidades ribeirinhas está intimamente ligada a relação que se faz entre o rio e o meio urbano. Mello (2008, p. 300) destaca que "a cidade nasce da água. A história urbana pode ser traçada tendo como eixo as formas de apropriação das dinâmicas hídricas. A trajetória das relações entre cidade e corpos d'água reflete, assim, os ciclos históricos das relações entre homem e natureza".

Mello (2008) classifica dois tipos mais simples de relações entre cidades e seus corpos d'água, que podem ser usados como parâmetro para o entendimento da presente pesquisa. Na primeira relação, o corpo d'água é valorizado e incorporado à paisagem urbana, o que geralmente acontece com rios e lagos de maior porte. Na segunda relação o corpo d'água é desconsiderado, as edificações e lotes lindeiros ficam de costas para ele; frequentemente os cursos d'água de menor porte são recobertos, tornando-se dutos de esgotos (MELLO, 2008). Corroborando o autor, Morsh, Marcaró e Pandolfo (2017) destacam que reintegrar os rios urbanos à paisagem e proporcionar boa conexão entre o homem e o corpo hídrico são desafios para as cidades brasileiras.

A desvalorização da paisagem ribeirinha, lembra o potencial perdido, que é caraterizado por Ghilardi e Duarte, quando afirmam que "os rios urbanos quando valorizados como recurso natural nos espaços livres da cidade, atraem as pessoas e, deste modo, são capazes de dar suporte a uma vida pública, e contribuir para aumentar o papel social do entorno ribeiro" (GHILARDI, DUARTE, 2006, p. 116).

Ainda vale lembrar que "a identidade se manifesta pela consciência de que os cursos d'água são bens comuns, ou seja, pelo sentimento de pertença e que merecem cuidado, o desejo de proteger" (MELLO, 2008, p. 274). Sob esse ponto de vista, fica nítida a importância da conscientização da população sobre o papel dos rios urbanos e da sua relevância, não só como paisagem, mas como bem comum, além da promoção de atividades que tornem esses locais parte integrante do cotidiano de todos. Assim, o uso da paisagem ribeirinha deve considerar não apenas as funções ambientais conferidas a ela, mas também analisar questões no que diz respeito à próprias funções de espaços livres, "tais como o lazer, a circulação, a fruição das paisagens e da vida pública cotidiana" (SOUZA, MACEDO, 2014, p. 13)

Portanto, faz-se necessário que os rios urbanos, assim com as margens ribeirinhas sejam não só preservadas, como também valorizadas em seu âmbito físico, visual e vegetal. As margens preservadas, muitas vezes escondem a inércia civil e governamental com relação a poluição das águas, logo, quanto antes for enfrentado este problema, maiores benefícios serão entregues para a população. Lembrando sempre que devem ser respeitadas as funções naturais desses ecossistemas, para que sua dinâmica de 
funcionamento não seja alterada, para que haja uma relação harmoniosa entre solo, energia, água e seres humanos.

\title{
Função social dos rios
}

Consciente do significado de urbanidade, Mello (2008) assegura que esse aspecto dos espaços em margens urbanas, que engloba um conjunto de fatores - aspectos sintáticos e semânticos - influencia o grau de valorização dos rios pela população, mas ressalta-se que não é um valor único. Outro valor, muito importante neste processo de valorização das águas urbanas, é o papel social que essas águas representam e como a população age diante dos rios. Saraiva esclarece que:

\begin{abstract}
O posicionamento relativo, social e individual, face a determinadas opções de gestão, pode ser modificado por ações de sensibilização e educação ambiental, apontando geralmente num sentido de maior sensibilidade a objetivos de equilíbrio com a natureza. É por esta razão que uma das principais metas na prossecução de um desenvolvimento sustentável, tema referencial da atual década [1990], consiste no esforço de educação ambiental como principal objetivo para o seu alcance (SARAIVA, 1999, p. 3).
\end{abstract}

Vale destacar que o conceito de função social é cumprido quando atende às exigências fundamentais de ordenação da cidade expressas no plano diretor. Além disso, a função social da propriedade se refere ao limite que deve ter seu possuidor de usufruí-la diante das carências sociais e também diante das irracionalidades causadoras da depredação ambiental. Logo, a função social dos rios pode ser assimilada de maneira paralela, atendendo a funções de ordenamento, estruturação, lazer e paisagem para todos do município.

Saraiva (1999, p. 381) assegura que "os benefícios disponibilizados à sociedade pelos cursos d'água exprimem diversos valores e assumem várias funções. Os valores podem ser considerados de dois tipos, de uso e de não uso". Os primeiros, valores de uso, vão desde abastecimento de água, energia e transporte, até recreio, pesca, entre outros. "Os valores de não-uso constituem aspectos reconhecidos pela sua validade para a sociedade, como sejam, por exemplo, os valores paisagísticos, os históricos culturais, a integridade natural, e a raridade de determinados ecossistemas" (SARAIVA, 1999, p. 382).

As margens de rios, podem ser transformados em locais de práticas de esportes e lazer contemplativo, que devido sua extensão podem formar um grande sistema de parques, como afirma Pellegrino:

\begin{abstract}
A existência de um sistema de parques e corredores integrados deverá facilitar o acesso da população a equipamentos esportivos e recreativos. A desconcentração das áreas de lazer permite uma melhor apropriação das mesmas, gerando também uma maior oferta de espaços livres [...]. Além disso, prevê-se a existência de roteiros culturais e de educação ambiental. Em locais com interesse ecológico-educacional podem ser desenvolvidas parcerias com escolas e universidades, de modo a promover roteiros educativos (PELLEGRINO, 2006, p. 65).
\end{abstract}

Ao relacionar os rios urbanos com sua devida função social, Saraiva (1999, p. 397) afirma que "a participação do público é uma etapa indispensável nos processos de ordenamento do território e do planejamento ambiental dos recursos naturais". Ela assegura por fim que a educação ambiental tem caráter de extrema importância nos diversos grupos que compõem a sociedade, que deve refletir as visões existentes sobre a relação entre desenvolvimento e ambiente.

\section{EXPANSÃO DA CIDADE DE TERESINA E SEUS RIOS}

No estado do Piauí, as bacias hidrográficas foram determinantes para sua implantação e povoamento, sendo de extrema importância para que algumas particularidades do território piauiense se desenvolvessem, como ocorreu em Oeiras, primeira capital do estado, que foi implantada às margens do rio Piauí.

Em Teresina, dois importantes corpos hídricos marcam a paisagem da cidade, e foram indispensáveis para que a cidade se desenvolvesse e assumisse o papel de nova capital, são eles os rios Parnaíba e Poti. A implantação de seu contexto urbano nas proximidades do rio Parnaíba teve como justificativa principal a questão econômica, visto que facilitaria o escoamento dos produtos, e comunicaria de maneira mais eficaz a capital com o resto da província (CHAVES, 1987). 
A área escolhida se caracterizava pelo grande potencial pautado na facilidade de escoamento resultante da proximidade com dois cursos d'água, os rios Poti e Parnaíba. Esse local que marcou o início da construção da cidade corresponde ao atual Centro de Teresina, na margem do rio Parnaíba.

O sítio no qual a cidade está locada beneficiava seu processo de expansão por apresentar relevo não acidentado e de difícil inundação, caracterizado por cotas mais elevadas, que, desta forma, não condicionava evolução urbana da Capital (CHAVES, 1987).

A transferência da capital para Teresina, em 1852, proporcionou uma importante reformulação urbana na cidade que teve início com o Plano Saraiva, o primeiro dos planos urbanísticos pelos quais a cidade viria a se nortear, instituído pelo, então presidente da província, Conselheiro Saraiva. Segundo Saraiva todo o planejamento urbano deveria ter o rio Parnaíba como referência em virtude do fluxo comercial que o mesmo fomentava, enquanto o traçado deveria seguir a ortogonalidade (CHAVES, 1987).

O intervalo de tempo entre os anos de 1900 e 1950 foi marcado pela implantação da linha férrea (1921), partindo das proximidades do rio Parnaíba, e pelo permanente protagonismo desse rio quanto à articulação econômica da cidade. Um dos fatores que contribuíram para tal potencial foi a construção da Avenida Maranhão, paralela ao mesmo rio, durante esse período, que proporcionou um maior contato e interação do curso d'água com outros bairros, além de tornar o centro da cidade mais dinâmico, assim como a construção da primeira ponte da capital, Ponte João Luís Ferreira ainda sobre o rio Parnaíba (1939), popularmente conhecida como Ponte Metálica (MATOS, 2017).

Já no intervalo entre os anos de 1950 e 1960, as modificações que começaram a aparecer representaram mudanças determinantes para que a capital atingisse a configuração urbana que conquistou até as décadas atuais (FAÇANHA, 1998). Neste momento a cidade também sofreu uma série de intervenções de caráter estruturante, ou seja, ações que estavam relacionadas a melhorias na infraestrutura urbana, como a construção do Centro Administrativo na zona Sul, a instalação do Distrito Industrial, a abertura das Avenidas Miguel Rosa, que contorna o bairro Centro, Avenida Barão de Gurguéia e Avenida ribeirinha Maranhão, margeando o rio Parnaíba, que atualmente permanecem como algumas das principais avenidas da cidade (FAÇANHA, 1998).

Todas essas vias contribuíram para a expansão da cidade no sentido sul, enquanto no sentido leste houve a construção da Ponte Juscelino Kubitschek (1957), superando a importante barreira natural que foi o rio Poti. Assim, Lima (2002) indica que, a partir de 1950, a Avenida Frei Serafim se tornou a grande impulsionadora da expansão no sentido leste, ligando-se à BR 343 (Avenida João XXII). Logo, pode-se afirmar que a construção dessas avenidas e da Ponte Juscelino Kubitschek foi determinante para o crescimento da cidade no sentido do rio Poti, distando cerca de 500 metros do centro cívico da capital.

Ainda na década de 1960 foi elaborado o Plano de Desenvolvimento Local Integrado - PDLI (TERESINA, 1969), um importante plano urbanístico da capital, por ser o primeiro a abordar a temática urbana depois da implantação do Plano Saraiva. Esse plano defendia a necessidade de expansão da cidade no sentido leste, caracterizando as zonas norte e sul como áreas de risco, objetivando munir a cidade com uma infraestrutura que atendesse tais requisitos (MATOS, 2017).

Já as décadas de 1970 e 1980 foram marcadas pela expansão das zonas norte (objeto de estudo desse trabalho) e sul de maneiras distintas, uma vez que, enquanto na direção norte a cidade crescia pela ocupação de grandes lotes, na zona sul implantavam-se importantes conjuntos habitacionais, como o Parque Piauí, diversificando ainda mais o uso da região, que anteriormente já havia recebido o Distrito Industrial (FAÇANHA, 1998). Nessa época também aconteceu a construção da Universidade Federal do Piauí - UFPI (em 1970), nas proximidades do rio Poti, fomentando a urbanização acelerada da zona leste e sua consequente valorização. Em 1979 foi construída a Ponte Ministro Petrônio Portella sobre o rio Poti, objetivando amenizar a demanda pela valorização da área.

A década também foi marcada pela implantação do primeiro Plano Estrutural de Teresina - I PET (TERESINA, 1977), que fomentou a ocupação de determinadas áreas, o que ocorreu (paralelamente) de forma regular e irregular. O plano classificou a zona Norte como inundável, comprometendo sua expansão, enquanto as extremidades das zonas Leste e Sul foram tidas como ocupáveis, fomentando sua expansão e indicando, dessa forma, a tendência de crescimento na época (MATOS, 2017).

Segundo Façanha (1998), a década de 1980, em especial, foi marcada pela descentralização do comércio na cidade, o que determinou a expansão da cidade em todas as direções. Além do comércio, a construção civil também se expandiu determinando a verticalização de alguns bairros da zona Norte, dentre eles o Cabral, Frei Serafim e Ilhotas. Já o II Plano Estrutural de Teresina - II PET, datada do ano de 1988 (TERESINA, 1988a), trouxe grande evolução no aspecto ambiental, sem deixar de lado o incentivo à expansão e urbanização da capital. Partindo da ideia que as zonas Norte, Sul e Centro, abraçadas pelos 
rios Poti e Parnaíba, estavam em estado limite de atividades, o plano apostou na expansão e aparelhamento da zona Leste como uma forma de amenizar esse quadro de sobrecarga.

$\mathrm{Na}$ década de 1990, os setores de serviços e de comércio permaneceram como forma de sustento da economia de Teresina, os quais foram crescendo à medida que a cidade estava se expandindo. Destaca-se também que o aparecimento de áreas irregulares, como vilas e favelas, assim como o surgimento de bairros, foram fatores que colaboraram para os núcleos de comércios e serviços se ampliarem. Vale ressaltar, que juntamente com estes setores, o setor industrial e as construtoras imobiliárias também se proliferaram, adquirindo novas estratégias por toda a cidade, descentralizando-se e potencializando os investimentos imobiliários (FAÇANHA, 2003). Nessa mesma década cabe enfatizar, ainda, que o processo de verticalização ganhou destaque, desenvolvendo-se em novas direções, com prédios implantados em áreas mais nobres, como nos bairros Jóquei e Fátima. Façanha (2003) afirma também que a concentração de construções voltadas à moradia e comércio muda do bairro Centro para as proximidades dos bairros que englobam o Riverside Shopping e o Teresina Shopping, ambos construídos na década de 1990. É importante evidenciar que os dois shoppings foram separados entre si por uma distância de aproximadamente um quilômetro, os quais propiciam novos serviços e acarretam no surgimento de novas centralidades, mudando o comportamento da população de Teresina.

A partir dos anos 2000 a cidade teve grande crescimento no sentido norte, em virtude, sobretudo, da Ponte Mariano Gayoso construída na década de 1990 e da Ponte Leonel Brizola em 2011. Destaca-se ainda, que, várias outras pontes foram construídas ao longo desses anos aos dias atuais, tanto para conectar bairros e zonas como também para desafogar o trânsito, como foi o intuito da Ponte Mestre João Isidoro França (2010), mais conhecida como Ponte Estaiada, a qual liga as zonas Centro/Norte e Leste.

Quanto aos planos urbanísticos, houve o Plano de Desenvolvimento Sustentável no ano de 2002 (TERESINA, 2002), e em 2006 (TERESINA, 2006a) foi proposto um novo plano diretor para a cidade que tinha como um de seus objetivos controlar a expansão provocada pelos outros planos. Além disso, houve também a elaboração das Agendas 2015 e 2030, documentos de grande importância que focam na questão do desenvolvimento sustentável na capital.

Já em 2019, foi aprovado o Plano Diretor de Ordenamento Territorial - PDOT (TERESINA, 2019), tendo como objetivo geral orientar a Política de Desenvolvimento Territorial do Município, sendo instrumento básico da política de desenvolvimento e ordenamento territorial, definindo as diretrizes para os planos setoriais, os instrumentos e normas urbanísticas para sua implantação e para a gestão territorial, destacando ainda as mudanças em relação as áreas de Zonas de Preservação - ZP.

\section{Instrumentos regulatórios (Legislação Municipal)}

$\mathrm{Na}$ cidade de Teresina - PI, com a Lei Municipal $\mathrm{n}^{\circ}$ 1.939/88 (TERESINA, 1988b), as margens dos rios Parnaíba e Poti passaram a ser consideradas como Zonas de Preservação - ZP, resultando nas primeiras ações de preservação efetiva nas margens dos rios da capital, por parte da Prefeitura. Com essa iniciativa tornou-se claro o distanciamento das medidas de caráter mais estrutural que prevalecia até então.

Quanto às áreas de preservação, foram implementadas as Zonas de Preservação Ambiental - ZP's concebidas por meio da Lei Municipal e atualizada pela Lei Complementar $n^{\circ} 3.563$, de 20 de outubro de 2006 (TERESINA, 2006b), que estabelece zonas de preservação ambiental, introduz normas de proteção de bens de valor cultural e garante outras decisões. Essas ZP's, no âmbito municipal, geralmente são as APP's pressuposta na revisão do Código Ambiental Florestal.

A Lei Municipal (TERESINA, 2006b) determina oito áreas de preservação, sendo que as Zonas de Preservação 5 - ZP5 consistem nas áreas marginais dos rios e as Zonas de Preservação 8 - ZP8 também representam áreas nas proximidades dos rios, porém, sem abranger as ZP5, assim

§ 1ㅇ A Zona de Preservação Ambiental 1 (ZP1) compreende a Praça Marechal Deodoro e várias quadras próximas, conforme delimitação prescrita no Anexo 1 desta Lei Complementar.

$\S 2^{\circ}$ A Zona de Preservação Ambiental 2 (ZP2) compreende os lotes lindeiros à Avenida Frei Serafim, entre a Igreja São Benedito e a Avenida Marechal Castelo Branco.

$\S 3^{\circ}$ As Zonas de Preservação Ambiental 3 (ZP3) compreendem imóveis individualizados, situados no território do município.

$\S 4^{\circ}$ As Zonas de Preservação Ambiental 4 (ZP4) compreendem as praças e parques do município. 
$\S 5^{\circ}$ As Zonas de Preservação Ambiental 5 (ZP5) compreendem:

I - as encostas com declividades superiores a $30 \%$ (trinta por cento); II - as áreas marginais ao Rio Parnaíba, correspondentes a uma faixa com largura de $200 \mathrm{~m}$ (duzentos metros), salvo quando já estejam ocupadas, caso em que a faixa tem a largura da área ainda não ocupada; III - as áreas marginais ao Rio Poti, correspondentes a uma faixa com largura de $100 \mathrm{~m}$ (cem metros), salvo quando já estejam ocupadas, caso em que a faixa tem a largura da área ainda não ocupada; e IV - as áreas das lagoas e respectivas margens, correspondentes a uma faixa de $30 \mathrm{~m}$ (trinta metros).

§ 6을 As Zonas de Preservação Ambiental 6 (ZP6) compreendem as áreas de interesse paisagístico, de propriedade privada, que devem ser utilizadas para implantação de parques.

§ 7ํㅡㄹ Zs Zonas de Preservação Ambiental 7 (ZP7) compreendem os terrenos destinados à implantação de praças, nos loteamentos aprovados pela Prefeitura Municipal.

§ 8ํㅡㄹ Zs Zonas de Preservação Ambiental 8 (ZP8) compreendem áreas próximas aos rios, não integrantes das Zonas de Preservação Ambiental - ZP5 (TERESINA, 2006b, p.1).

Assim, a implementação dessa lei (Lei Municipal $n^{\circ} 1.939$, de 1988) foi uma iniciativa muito importante para que os rios fossem incorporados no planejamento urbano, além do fato de objetivar a criação das Zonas de Preservação Ambiental - ZP.

Porém, apesar da Lei ter sido de grande relevância para impedir ocupações e intervenções urbanas nessas áreas ambientais, focando na preservação da paisagem ribeirinha, ainda existem áreas ambientais que não apresenta uma real integração com o meio urbano. Há ainda porções consideráveis de áreas intocáveis, com pouco ou nenhum elemento de reestruturação que conecte ou aproxime os rios com a sociedade, a fim de mantê-las preservadas. Desse modo, percebe-se que a iniciativa foi bastante inovadora, porém ainda carece de ações mais efetivas por parte das autoridades públicas.

\section{BAIRROS RIBEIRINHOS DA ZONA CENTRO/NORTE}

Esse item busca analisar a relação que se tem entre o crescimento urbano da zona Centro/Norte de Teresina e a paisagem ribeirinha a partir do plano urbanístico de 1988 até os dias atuais. Ressalta-se que a capital piauiense é dividida pela Prefeitura de Teresina em cinco áreas correspondente às Superintendência de Desenvolvimento Urbano - SDUs e uma abrangendo a Superintendência de Desenvolvimento Rural SDR. As SDUs correspondem às zonas Centro/Norte, Leste, Sudeste, Sul, porém, o trabalho possui um enfoque para a zona Centro/Norte, na qual foram destacados elementos importantes que favorecem ou não a conexão do meio urbano com a paisagem ribeirinha (Figura 1).

Figura 1: Teresina e suas zonas.

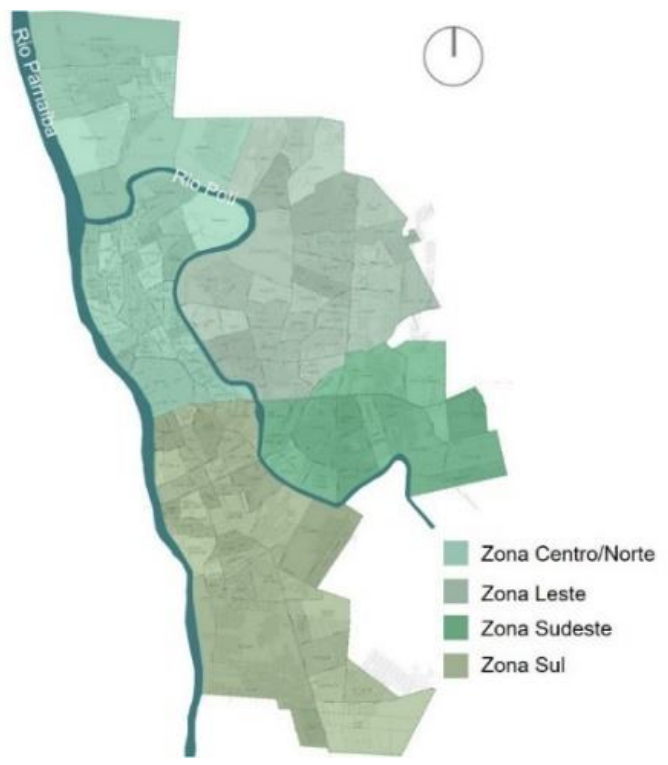

Fonte: https://semplan.teresina.pi.gov.br/wp-content/uploads/sites/39/2018/09/Teresina-Bairros-2013.pdf. Adaptado por Denise Santiago (2020). 
A zona Centro/Norte possui 40 bairros, incluindo o Centro da cidade. Dentre eles 25 são ribeirinhos, dos quais 14 estão localizados na margem ribeirinha do rio Poti e 09 na margem do rio Parnaíba. Destaca-se, ainda, 2 bairros que são margeados pelos dois rios (bairros Santa Rosa e Olarias). O estudo em questão foi dividido em 9 cenários formados por bairros ribeirinhos (Figura 2).

Figura 2: Zona Centro/Norte com seus bairros ribeirinhos e a formação de cenários.

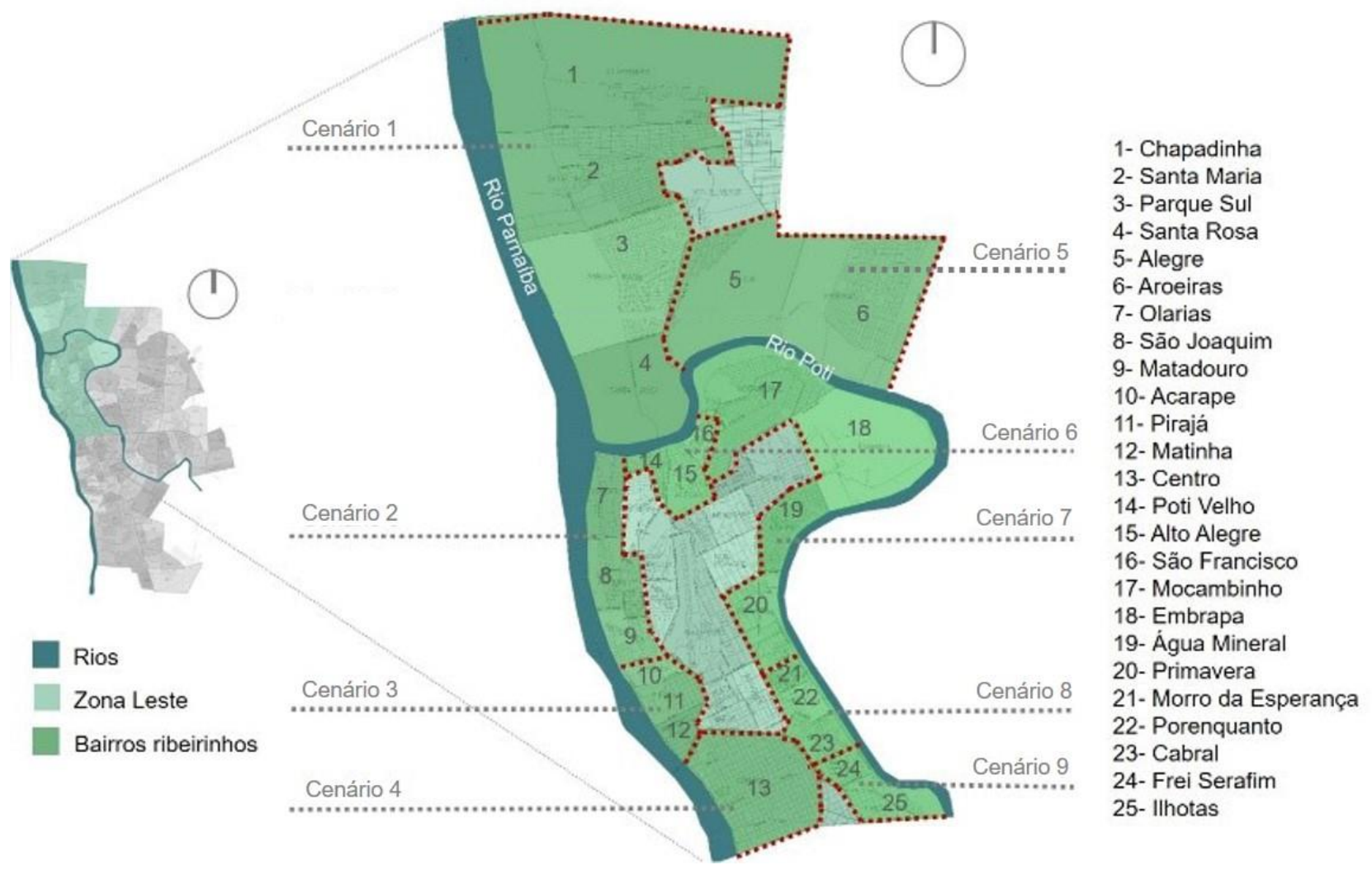

Fonte: https://semplan.teresina.pi.gov.br/wp-content/uploads/sites/39/2018/09/Teresina-Bairros-2013.pdf. Adaptado por Denise Santiago (2020).

Assim, para melhor compreensão das áreas, a análise foi dividida em 4 cenários na margem do rio Parnaíba e 5 cenários na margem do rio Poti. Assim, o primeiro cenário corresponde aos bairros ao norte do rio Poti localizados na margem do rio Parnaíba: Chapadinha, Santa Maria, Parque Sul e Santa Rosa, são bairros novos, construídos depois da década de 1990. Os mesmos são formados por conjuntos habitacionais populares, porém com muitos vazios urbanos em toda área. É válido destacar que o bairro Santa Rosa é margeado pelos rios Poti e Parnaíba, e por ele passa a Rua João Isidoro França, a qual divide o bairro ao meio. A rua também percorre por todos os bairros do cenário, ao longo do rio Parnaíba, e distante do mesmo. (Figura 3).

Em boa parte das margens ribeirinhas são acrescentadas ZP8 na faixa ZP5 dos bairros, além de ZP6 no bairro Santa Rosa. Toda essa área destinada para zona de preservação, encontra-se sem uso e com mata fechada, o que acaba distanciando a sociedade dos rios. Quanto ao acesso para os bairros além do rio Poti, é possível através da Ponte Mariano Gayoso (1991).

O segundo cenário engloba os bairros Olarias, São Joaquim e Matadouro, o primeiro margeado pelos rios Poti e Parnaíba, e os outros dois somente pelo rio Parnaíba. São os bairros mais antigos da cidade de Teresina, implantados na década de 1960 e constituídos por ocupações espontâneas em áreas inundáveis. Além disso, possuem topografia baixa, lagoas e uma forma de subsistência e de valores simbólicos relacionados aos rios.

No bairro Olarias, é marcante a presença da lagoa dos Oleiros. Porém, ao invés de ser potencializada, é comum a implantação de ocupações irregulares nas suas margens e nas margens dos rios Poti e Parnaíba. Nesse mesmo bairro, há o Parque Ambiental Encontro dos Rios (1990), espaço livre bastante utilizado 
Matos, K. C; Santiago, D. R; Lopes, W. G. R; Silva, I. M. G. P; Leite, N. B. F;

pelos teresinenses e turistas, no qual se destaca o Monumento do Cabeça de Cuia na entrada (a), local para vendas de artesanato e playgroung (b) e o Restaurante Flutuante (c) (Figura 4).

Figura 3: Cenários ao longo do rio Parnaíba.

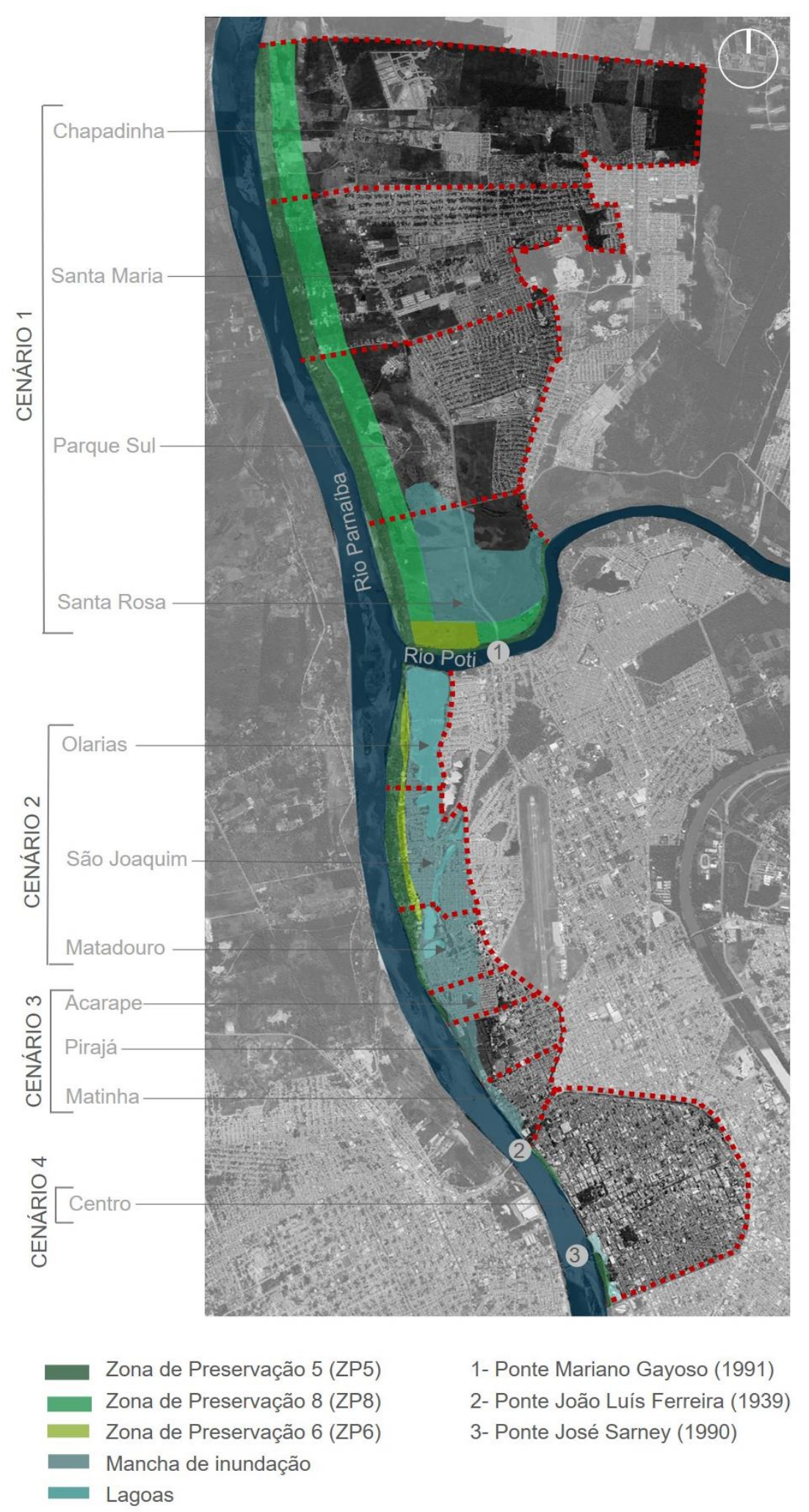

Fonte: https://semplan.teresina.pi.gov.br/wp-content/uploads/sites/39/2018/09/Teresina-Bairros-2013.pdf. Adaptado por Denise Santiago (2020). 
Matos, K. C; Santiago, D. R; Lopes, W. G. R; Silva, I. M. G. P; Leite, N. B. F;

Figura 4: Parque Ambiental Encontro dos Rios (1990).
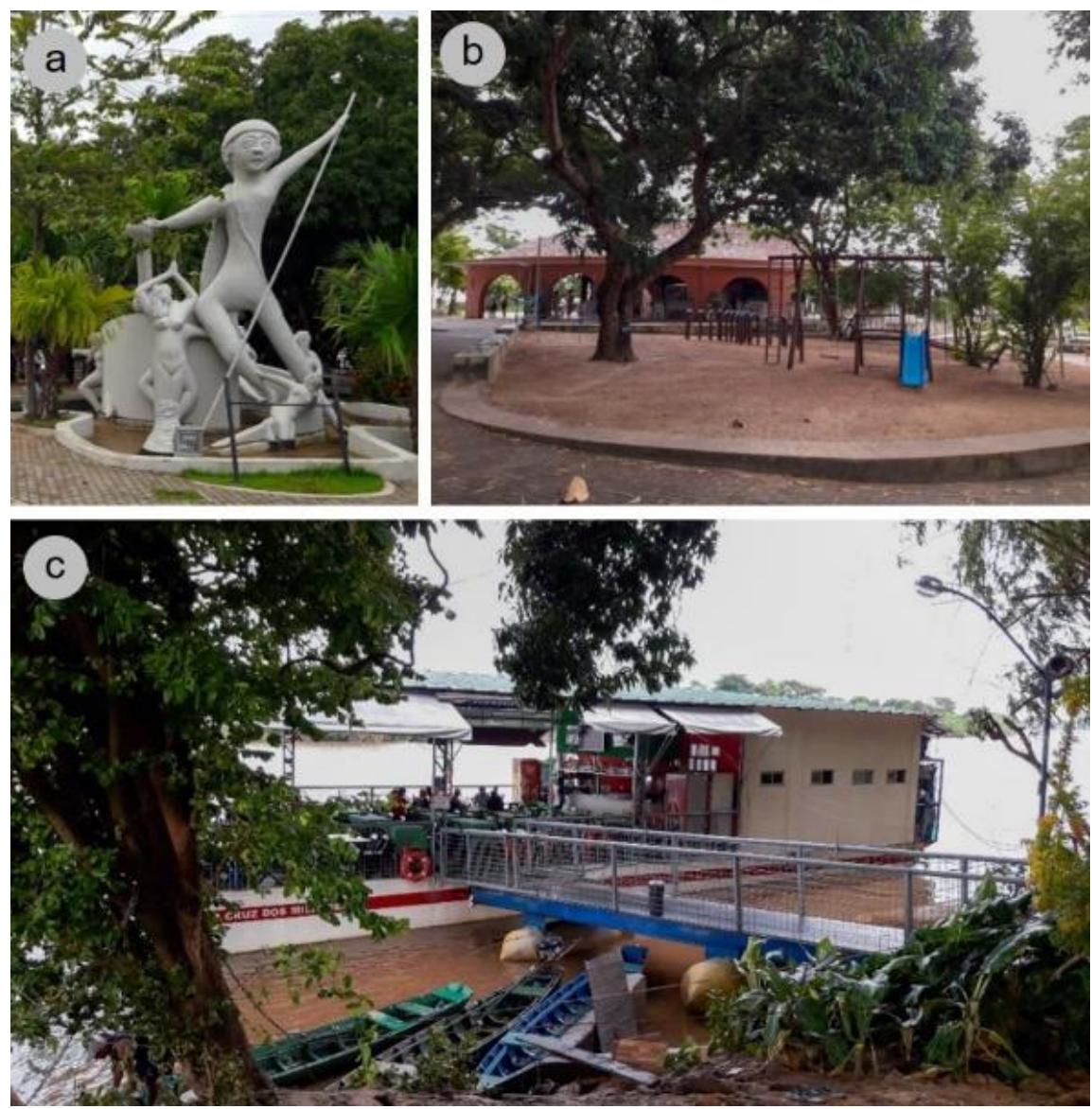

Fonte: Denise Santiago (2020).

Quanto aos bairros São Joaquim e Matadouro, possuem população com perfil social de renda baixa e traçado irregular com casas simples. Nesses bairros, a presença de lagoas também marca a paisagem, porém, muitas vezes são desprezadas pela população e pela Prefeitura de Teresina, tornando-se apenas fundos de lotes ou lugar onde as pessoas jogam seus lixos. Vale destacar que no bairro São Joaquim há hortas comunitárias e de vazantes e que no bairro Matadouro que se deu início ao Projeto Lagoas do Norte ${ }^{1}$.

Nas frentes ribeirinhas dos bairros passa a Avenida Boa Esperança, que tem seu início no Parque Encontro dos Rios e se estende até o limite do bairro Matadouro. É uma avenida estreita, na qual passa os mais diversos modais, como carros, bicicletas e até mesmo ônibus. Além disso, é uma avenida dique de proteção das cheiras do rio Poti.

O terceiro cenário envolve os bairros Acarape, Pirajá e Matinha, os quais também fazem parte das áreas mais antigas da cidade e que são atingidas por inundações, além de estarem mais próximo do Centro. Essa região apresenta perfil social com renda média-baixa. É importante destacar, que não há relação de dependência com o rio Parnaíba para a subsistência, como acontece nos bairros Olarias, São Joaquim e Matadouro.

No limite entre o bairro Matadouro e Acarape se inicia a Avenida Maranhão, larga, arborizada e que proporciona melhor conexão visual com o rio Parnaíba. O bairro Acarape funciona como área de transição entre uma paisagem mais rural para uma paisagem mais urbana.

Nos outros dois bairros, há grandes elementos que marcam a paisagem, como o aqueduto pela sua arquitetura, no terreno da Águas de Teresina ${ }^{2}$, no bairro Pirajá, e o late Clube, no bairro Matinha, considerado um espaço de lazer na cidade. Vale destacar que nesse mesmo bairro as margens ribeirinhas são utilizadas pelos lavadores de carro ocasionando certa desvalorização à paisagem. 
O quarto cenário compreende o bairro Centro, que, a princípio, é válido destacar que possui características bem diferentes dos demais e se encontra nesse estudo por fazer parte da divisão determinada pela Prefeitura de Teresina.

O bairro Centro mantém o traçado regular do Plano Saraiva com um número considerável de ruas perpendiculares ao rio Parnaíba. Tal cenário, permite acesso mais facilmente às frentes do corpo hídrico. Além disso, permanece os principais espaços públicos, correspondendo as sete praças do plano Saraiva e ao passeio da avenida Frei Serafim.

No Bairro Centro, antes predominava o uso residencial, e, atualmente, além do uso residencial, também está presente os comércios e serviços. Com isso, a circulação de veículos aumentou e muitos dos lotes edificados ou vazios, passaram a servir como estacionamento. Ademais, vários outros fatores negativos foram sendo perceptíveis com essa mudança de usos, como a perda do patrimônio arquitetônico, o aumento do comércio informal e o trânsito lento, o que resultou em uma imagem de descaso com a cidade.

Os principais marcos urbanos da cidade estão nesse quarto cenário, que são: a Ponte João Luís Ferreira, mais conhecida como Ponte Metálica, e a Igreja Matriz Nossa Senhora do Amparo, correspondendo ao marco zero da cidade de Teresina.

Sobre a zona de preservação desse bairro no trecho ao longo do rio Parnaíba, a ZP5 é quase zero tomada pelas áreas impermeáveis. Ressalta-se ainda duas grandes áreas verdes, as quais correspondem às praças Marechal Deodoro e Da Costa e Silva, conhecida popularmente como Praça da Cepisa. A Praça Marechal Deodoro foi a primeira da cidade e possui relação histórica e simbólica. Já a Praça Da Costa e Silva, projetada pelo paisagista Roberto Burle Marx e arquiteto Acácio Gil Borsoi, representa um momento de modernização da cidade e de valorização da paisagem ribeirinha.

Nessa região encontra-se o Shopping da Cidade, empreendimento comercial implantado em frente à Praça Marechal Deodoro, em quarteirão voltado para o rio Parnaíba. Além disso, encontra-se também o Trocatroca, espaço aberto com cobertura formada por abóbodas e localizado ao lado do antigo cais. Refere-se ao local onde está presente o comércio informal de vendas e trocas de mercadorias.

É nesse bairro também que se encontra duas das três pontes que liga Teresina com a cidade de Timon-MA, são elas: Ponte João Luís Ferreira (1939) e Ponte José Sarney (1990).

Os próximos cenários são margeados somente pelo rio Poti, assim, o quinto cenário abrange os bairros Alegre e Aroeiras, localizados na margem ao Norte do rio Poti (Figura 5).

Os mesmos apresentam infraestrutura básica, sem espaços de lazer, longes do Centro da cidade e com perfil social de renda baixa. Por eles passa a Avenida Dr. Josué de Moura Santos, ribeirinha, porém, longe do rio Poti. Assim como no primeiro cenário, o distanciamento entre a avenida e o rio ocorre pela adição da ZP8 à ZP5, além da ZP6 presente no bairro Aroeiras. Ademais, há a presença de outra ponte nessa zona, a Ponte Leonel Brizola (2011), sendo possível fazer a integração dessa região com os outros bairros.

O sexto cenário abrange três bairros margeados pelo rio Poti, são eles: São Francisco, Alto Alegre e Poti Velho. Os bairros São Francisco e Alegre, possuem pouca dimensão, assim como o bairro Poti Velho, porém, são pouco conhecidos. Além disso, também possuem baixo poder aquisitivo e sem infraestrutura básica.

Pelo bairro Poti Velho, passa a rua Flávio Furtado, via/dique que margeia o rio Poti, de pouca largura e trânsito intenso, uma vez que, dar continuidade à Avenida Boa Esperança. Ao longo dessa via encontra-se o centro de artesanato e residências que também funcionam como oficinas dos artesãos.

O bairro Poti Velho é formado por edificações simples, próximas umas das outras e sem muros. A população em geral possui baixo poder aquisitivo e pouca infraestrutura básica. Ainda sobre o mesmo bairro, possui grande significado cultural com rios, a pesca, as lendas e as atividades em barro. Ademais, possui forte religiosidade relacionada a São Pedro, o padroeiro dos pescadores.

O sétimo cenário corresponde aos bairros Mocambinho, Embrapa, Água Mineral e Primavera. São bairros de classe baixa, casas de um pavimento e muradas, e principais avenidas com uso comercial. Diferente dos bairros do cenário anterior, os bairros em questão não possuem atividades relacionadas com o rio, como a pesca e $o$ artesanato.

O bairro Mocambinho é quase todo constituído pelo conjunto habitacional de mesmo nome, projetado pelo arquiteto Acácio Gil Borsoi. O projeto teve um desenho urbanístico diferente, com o intuito de proporcionar melhoria na moradia para as pessoas mais pobres em área até então desvalorizada. 
O bairro Embrapa engloba uma área de experimentação agrícola, reservada para a instalação da sede da Empresa Brasileira de Pesquisas Agropecuárias (EMBRAPA). Dessa forma, boa parte do bairro encontra-se sem ocupações, contribuindo na preservação ambiental, uma vez que, é quase todo ocupado pela empresa. A região é inundável e acompanha a curva sinuoso do rio Poti. É válido enfatizar que o acesso ao rio Poti ocorre apenas pelos funcionários da Embrapa. Quanto as avenidas ribeirinhas o bairro Água Mineral também não possui nenhuma via que margeia o rio Poti, resultando em ocupações de costas para o corpo hídrico.

Figura 5: Cenários ao longo do rio Poti.

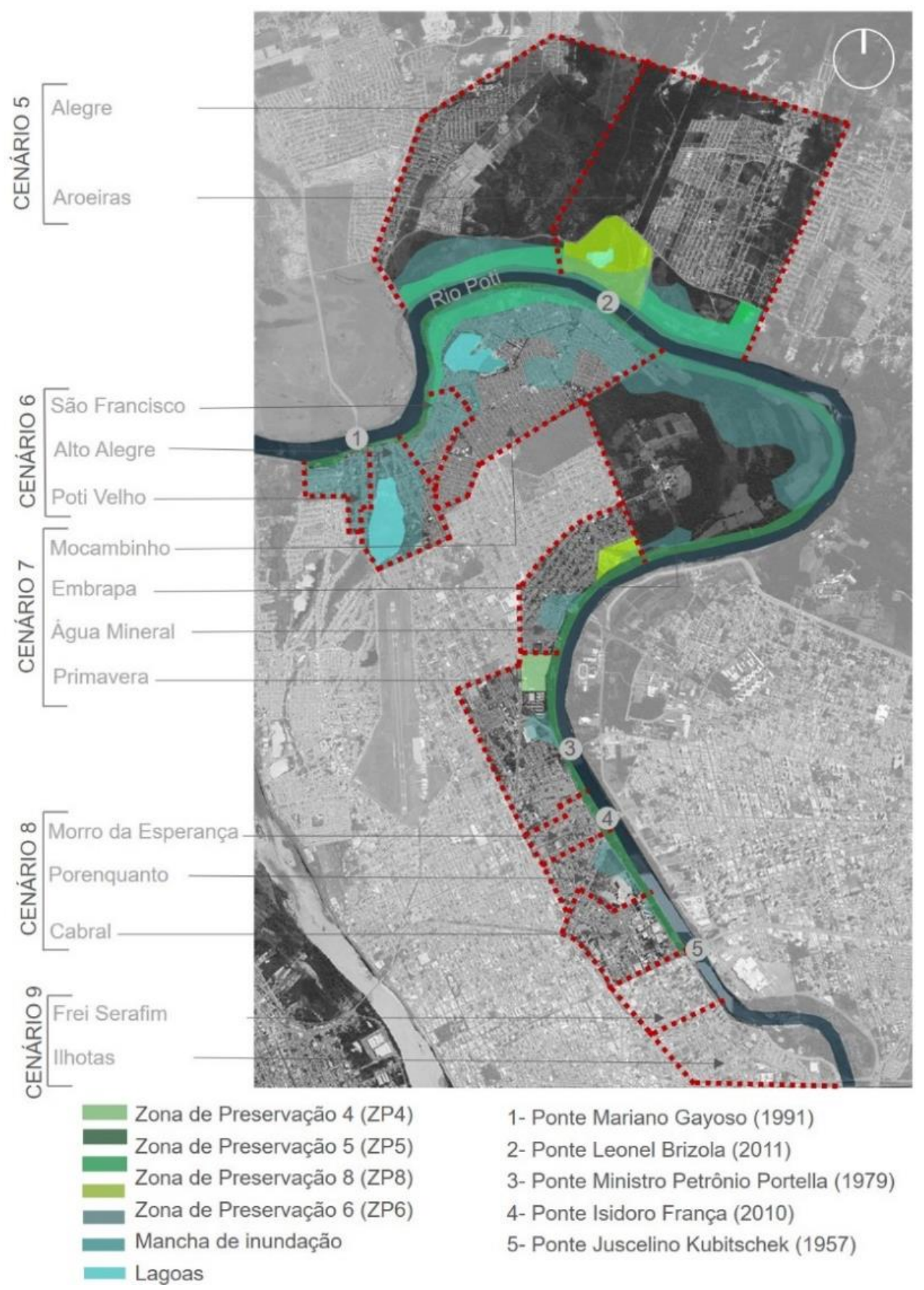

Fonte: https://semplan.teresina.pi.gov.br/wp-content/uploads/sites/39/2018/09/Teresina-Bairros-2013.pdf. Adaptado por Denise Santiago (2020).

O bairro Primavera possui em algumas áreas fluxos intensos, devido sua localização a qual incorpora a ponte que mais influencia os fluxos e atividades do bairro, a Ponte Ministro Petrônio Portella, ou Ponte da 
Primavera. Apesar de não ter sido determinante para sua implantação, certamente a ponte em questão foi decisiva no processo de expansão e articulação do bairro, uma vez que conecta o mesmo à zona Leste da cidade, anteriormente segregada das demais zonas pelo rio Poti, além de trazer um acesso alternativo para a Universidade Federal do Piauí, desafogando as pontes já existentes. Apresenta uma disposição de quadras predominantemente ortogonal, regularidade imprimida pelos conjuntos habitacionais que lhes deram origem.

Em relação ao meio ambiente, o bairro Primavera possui alguns espaços livres que proporcionam boa arborização para o bairro, como os parques Poti I e o Parque da Cidade. É nele também que se tem o início da Avenida Marechal Castelo Branco, ribeirinha, permitindo maior aproximação com o rio Poti.

O oitavo cenário engloba os bairros Morro da Esperança, Porenquanto e Cabral, todos localizados entre as pontes Ministro Petrônio Portella e Juscelino Kubitschek. O bairro Morro da Esperança possui topografia com declividade acentuada e quadras com ruas perpendiculares a Avenida Marechal Castelo Branco. Dentre essas, vale destacar a Avenida Alameda Parnaíba que dar acesso à Ponte Estaiada. Apesar de ser relativamente recente a construção da ponte, esta demostra grande influência nessa região, principalmente no que diz respeito ao aumento do fluxo nessa área.

Quanto à malha urbana, o bairro não cresceu muito em relação a alguns anos atrás, fato resultante principalmente do seu tamanho, formado por poucas quadras. Estas, por sua vez, se apresentam com formato ortogonal regular, com exceção de algumas descontinuidades dentro da área. Sobre os espaços livres, o bairro Morro da Esperança carece de espaços livres de lazer, apresentando apenas a extensão do Parque Ambiental Poti I na margem ribeirinha.

O bairro Porenquanto teve sua expansão marcada pela a construção do Sanatório Meduna, em 1954, o qual funcionou por mais de 56 anos. Esta edificação foi importante porque ocupava uma grande área do bairro, e na época estava isolada das áreas próximas, existindo nas proximidades apenas algumas casas e o Palácio da Justiça. Com o crescimento da área e da demanda por mais serviços e moradias, a maior parte do sanatório foi demolido para a implantação do Shopping Rio Poty (2015), torres comerciais e prédios residenciais, resultando em um novo cenário urbano.

Quanto à malha urbana, a maioria das quadras estão organizadas de forma ortogonal e regular, com exceção da área que abrange o Shopping Rio Poty, inserida em um recorte irregular e com declividade acentuada. Vale ressaltar que o bairro ainda possui grandes áreas livres, sobretudo perto do shopping, permitindo futura expansão. Assim como o bairro Morro da Esperança, o bairro Porenquanto, no que se refere aos espaços livres de lazer, apresenta apenas o Parque Ambiental Poti I na margem ribeirinha.

Sobre o bairro Cabral teve grande influência da Ponte Juscelino Kubistchek no seu processo de adensamento, principalmente pelo fato dessa ponte está limitando o perímetro do bairro. Destaca-se a importância desse bairro pela presença do centro cívico de Teresina e de outras edificações importantes na paisagem ribeirinha, como a Águas de Teresina (1962), Palácio da Justiça (1972), Assembleia Legislativa (1984), Câmara Municipal de Teresina, Fórum Cível e Criminal (2013), Tribunal Regional Eleitoral e o Centro de Convenções, todos edificados nas quadras mais próximas ao rio Poti. Quanta à malha urbana, boa parte das quadras estão organizadas de maneira ortogonal e regular, porém, vale destacar a região do centro cívico que apresenta trechos com descontinuidades. Nesse contexto, tem-se também o Parque da Cidadania configurado por lote de grande dimensão que não permite acesso direto por vias.

Quanto ao aspecto ambiental, o bairro possui o total de uma praça e dois parques que permite se ter áreas mais arborizadas no bairro. A praça é o espaço livre próximo ao Palácio, Praça Edgar Nogueira, e os Parques são o Parque Ambiental Rio Poti I ao longo da margem ribeirinha e o Parque Estação Cidadania, inaugurado no ano de 2016, que conta com áreas de lazer, anfiteatro e Galeria de arte.

O último cenário da zona Centro/Norte, corresponde aos bairros Frei Serafim e llhotas, localizados depois da Ponte Juscelino Kubitschek. Comparado a todos os bairros dessa zona, os dois bairros em questão, são os mais valorizados e os que tem maior quantidade de edifícios residenciais. Assim, suas frentes ribeirinhas são marcadas por essas edificações de alto padrão e pelo Rio Poty Hotel, com projeto paisagístico de Roberto Burle Marx. Nesse trecho, encontra-se o Parque Ambiental llhotas, que se conecta ao Parque Floresta Fóssil.

\section{CONSIDERAÇÕES FINAIS}

Esta pesquisa estudou o histórico da cidade de Teresina e sua expansão, relacionando-o com os Planos Urbanísticos, com destaque nos bairros ribeirinhos da zona Centro/Norte. Somado a isso, apresentou 
conceitos relacionados ao tema, como espaços livres e paisagem ribeirinha, os quais possibilitaram obter conclusões a respeito da paisagem ribeirinha dos rios Parnaíba e Poti no recorte estudado.

Assim, destaca-se que a cidade de Teresina se iniciou e se estruturou através dos rios Parnaíba e Poti, com seu zoneamento determinado a partir de planos urbanísticos e considerando, posteriormente, as diversas leis ambientais que foram surgindo ao longo do tempo. É possível perceber uma tentativa de preservação dos rios pela Prefeitura Municipal de Teresina a partir do final dos anos 1980, onde são definidas todas as áreas de rios como de Zonas de Preservação (ZP), acompanhando o limite mínimo definido pelo código Florestal. Nota-se que não basta apenas o poder público definir áreas como ZP, é preciso que o poder público entenda as particularidades de cada lugar, considerando seus aspectos físicos, sociais e ambientais, assim como também um planejamento participativo com a população do entorno, pois são essas pessoas que convivem diariamente com essa paisagem.

Diante das análises realizadas, foi possível perceber que os cenários que fazem parte da paisagem do rio Parnaíba, no recorte do encontro dos rios até o centro da cidade, apresentam uma relação mais direta com o rio, pois, atividades como a pesca e de hortas comunitárias ainda são comuns pelos moradores dos bairros ribeirinhos. Essas atividades vão se modificando à medida que se aproxima do bairro Centro, onde as atividades comerciais são ativas e as formas de ocupações são mais padronizadas. Os cenários que fazem parte da paisagem do rio Poti apresentam um certo distanciamento das suas práticas sociais, 0 Parque da Cidade pode ser considerado o lugar que tem hoje o maior potencial para aproximação. $O$ rio Poti, diferente do Parnaíba, não tem essa característica para atividades de subsistência, e tão pouco, nesse trecho em estudo há uma via que a acompanhe, ficando muitas vezes a margem do rio como fundo de lotes. Em relação aos parques ambientais ribeirinhos, todos eles, que fazem parte do recorte em estudo, estão abandonados, com exceção apenas do parque Encontro dos Rios.

Entende-se que as análises apresentadas têm potencial para contribuir positivamente para futuras pesquisas sobre rios urbanos, trazendo questões referentes à identificação de cenários para um posterior planejamento urbano e ambiental que considere as particularidades do lugar.

\section{AGRADECIMENTOS}

Agradecemos ao apoio financeiro da Fundação de Amparo à Pesquisa do Estado do Piauí - FAPEPI.

\section{REFERÊNCIAS}

CHAVES, J. R. F. Como nasceu Teresina. Teresina: Fundação Cultural Monsenhor Chaves, 1987.

FAÇANHA, A. C. Evolução de Teresina: agentes, processos e formas espaciais da cidade. Dissertação (Mestrado em Geografia). Universidade Federal de Pernambuco, Recife, 1998.

FAÇANHA, A. C. A evolução urbana de Teresina; passado, presente e... Carta CEPRO, Teresina, v.22, n.1, p.59-69, jan./jun. 2003.

GHILARDI, A. S.; DUARTE, C. R. de S. Ribeirão Preto: os valores naturais e culturais de suas paisagens urbanas. In: COSTA, L. M. S. A. (org.) Rios e paisagens urbanas em cidades brasileiras. Rio de Janeiro: Programa de Pósgraduação em Urbanismo. FAU/UFRJ, 2006, p. 95 - 119.

LIMA, I. M. M. F. Teresina: urbanização e meio ambiente. ScientiaetSpes. Teresina, ano 1, n. 2, p. 181-206, 2002.

MACEDO, S. S. Espaços Livres. Paisagem e Ambiente. São Paulo, 1995.

MACEDO, S. S. Quadro do paisagismo no Brasil. São Paulo: Edusp, 1999.

MAGNOLI, M. Espaço livre - objeto de trabalho. Paisagem e Ambiente, n. 21, p. 175-197, 30 jun. 2006.

MATOS. Karenina Cardoso. A cidade ribeirinha: desafios e possibilidades para o planejamento urbano-ambiental dos rios Parnaíba e Poti em Teresina-PI. Tese (Doutorado em Arquitetura e Urbanismo) - Universidade Federal de Santa Catarina. Florianópolis, 2017.

MELLO, S. S. de. Na beira do rio tem uma cidade. Tese (Doutorado em Arquitetura e Urbanismo) - Universidade de Brasília, Brasília, 2008.

MORSCH, M. R. S.; MASCARÓ, J. J.; PANDOLFO, A. Sustentabilidade urbana: recuperação dos rios como um dos princípios da infraestrutura verde. Ambiente Construído, Porto Alegre, v. 17, n. 4, p. 305-321, out./dez. 2017. 
PELleGRINO, P. R. M.; GUEDES, P. P.; PIRILLO, F. C.; FERNANDES, S. A. A paisagem da borda: uma estratégia para a condução das águas, da biodiversidade e das pessoas. In: COSTA, L. M. S. A. (Org.) Rios e paisagens urbanas em cidades brasileiras. Rio de Janeiro: Viana \& Mosley; Editora PROURB, 2006. p. 57-76.

SANT'ANNA, C. G. A infraestrutura verde e sua contribuição para o desenho da paisagem da cidade. Tese (Doutorado em Arquitetura e Urbanismo). Universidade de Brasília, Brasília, 2020.

SARAIVA, M. G. A. N. O rio como paisagem: gestão de corredores fluviais no quadro do ordenamento do território. Lisboa: Fundação Calouste Gulbenkian, 1999. 512p.

SALES, M. T. F. L. Percursos na paisagem. Tese (Doutorado em Gestão Interdisciplinar da Paisagem) - Instituto de Investigação e Formação Avançada, Universidade de Évora, Évora, 2015.

SOUZA, C. B.; MACEDO, S. S. APPs Fluviais Urbanas e Sistemas de Espaços Livres: O papel da legislação ambiental na configuração do espaço urbano à beira d'água. $3^{\circ}$ Seminário Nacional sobre o Tratamento de Áreas de Preservação Permanente em Meio Urbano e Restrições. Universidade Federal do Pará, Belém, 2014.

TERESINA. I Plano Estrutural de Teresina. Prefeitura Municipal de Teresina. Teresina, 1977.

TERESINA. II Plano Estrutural de Teresina. Prefeitura Municipal de Teresina. Teresina, 1988a.

TERESINA. Lei no 1.939 , de 16 de agosto de 1988. Cria zonas de preservação ambiental, institui normas de proteção dos bens de valor cultural e dá outras providências. Diário Oficial do Município. Teresina, 1988b.

TERESINA. Lei $\mathrm{n}^{\circ}$ 3.151, de 23 de dezembro de 2002. Institui o Plano de Desenvolvimento Sustentável - Teresina Agenda 2015 como o Plano Diretor de Teresina. Diário Oficial do Município. Teresina, 2002.

TERESINA. Lei no. 3.558, de 23 de dezembro de 2006. Reinstitui o plano diretor de Teresina, denominado Plano de Desenvolvimento Sustentável - Teresina Agenda 2015, e dá outras providências. Diário Oficial do Município. Poder Executivo, Teresina, PI, 23 de dezembro de 2006a.

TERESINA. Lei Complementar nํ 3.563, de 20 de outubro de 2006. Cria zonas de preservação ambiental, institui normas de proteção a bens de valor cultural e dá outras providências. Diário Oficial do Município. Poder Executivo, Teresina, PI, 20 de outubro de 2006b.

TERESINA. Lei Complementar no 5.481, de 20 de dezembro de 2019. Dispõe sobre o Plano Diretor de Teresina, denominado "Plano Diretor de Ordenamento Territorial - PDOT", e dá outras providências. Teresina, PI, 20 de dezembro de 2019.

\section{NOTAS}

${ }^{1}$ O Projeto Lagoas do Norte refere-se a uma iniciativa da Prefeitura Municipal de Teresina relacionada à drenagem para a região Norte, abrangendo o conjunto de lagoas existentes nas proximidades dos rios Parnaíba e Poti.

${ }^{2}$ Empresa responsável pelo abastecimento de água da cidade de Teresina.

NOTA DO EDITOR $\left(^{\star}\right)$ : O conteúdo do artigo e as imagens nele publicadas são de responsabilidade do(s) autor(es). 